\title{
PENGARUH MOTIVASI DAN KEPUASAN KERJA TERHADAP KINERJA PERSONIL DIREKTORAT KRIMINAL KHUSUS KEPOLISIAN DAERAH SUMATERA SELATAN
}

\author{
${ }^{1}$ Try Nensy Nirmalasary, ${ }^{2}$ Fakhry Zamzam, ${ }^{3}$ Luis Marnisah \\ ${ }^{1}$ Mahasiswa Program Magister Universitas IGM, Email:trynensynirmalasary21@gmail.com \\ ${ }^{2}$ Program Magister Universitas IGM, Email: fakhry@uigm.ac.id \\ ${ }^{3}$ Program Magister Universitas IGM, Email: luismarnisah@uigm.ac.id
}

\begin{abstract}
Job satisfaction and work motivation are directly related to personnel performance. Job satisfaction and work motivation felt by personnel can reduce performance or increase personnel performance. personnel who are satisfied with the work obtained will be motivated to improve performance so that it will have an impact on increasing overall organizational performance. This research was conducted at the Directorate of Special Criminal Investigation at the South Sumatra Regional Police, which aims to analyze how motivation and job satisfaction influence the performance of the Police Personnel at the Special Criminal Research Directorate for the South Sumatra Regional Police. The applied research model is a survey method, using 82 samples from a population of 92 Polri personnel at the Special Criminal Investigation Directorate for the South Sumatra Regional Police, using multiple regression analysis. The data analysis technique uses descriptive statistics and inferential statistics. In this study, the types of data used are primary data and secondary data. The data collection techniques used questionnaires, interviews, observation and documentation. Hypothesis testing through t test and F test using SPSS analysis tools. The results of data processing using SPSS 25, using the t test that t count is 4.021> with t table 1.993 and a significance level of $0.025<0.05$ that there is a positive and significant influence on motivation on performance; that $t$ count is $3.025>$ with $t$ table 1.993 and a significance level of $0.041<0.05$ that there is a positive and significant effect of job satisfaction on performance; and using the F test that $F$ counts at 7,194> with $F$ table 2.683 and a significance level of $0.00<0.05$ that there is a positive and significant effect on the pattern of motivation and job satisfaction together on performance, with a coefficient of determination of $49.3 \%$ the rest is influenced by other variables. The results showed that motivation and job satisfaction have a positive and significant effect on performance either partially or simultaneously. The career development strategy of the Police Personnel of the Directorate of Special Criminal Investigation at the South Sumatra Regional Police is very much determined by providing remuneration received by personnel on time according to applicable regulations, then increasing the work motivation of personnel with leadership techniques always giving appreciation for personnel work performance.
\end{abstract}

Keywords: Motivation, Job Satisfaction, Performance

\begin{abstract}
ABSTRAK
Kepuasan kerja dan motivasi kerja sangat berkaitan langsung dengan kinerja personel. Kepuasan kerja dan motivasi kerja yang dirasakan oleh personel dapat menurunkan kinerja ataupun meningkatkan kinerja personel. personel yang merasa puas dengan pekerjaan yang diperoleh akan termotivasi untuk meningkatkan kinerja sehingga akan berdampak pada meningkatnya kinerja organisasi secara keseluruhan. Penelitian ini dilakukan di Direktorat Reserse Kriminal Khusus Kepolisian Daerah Sumatera Selatan yang dimana bertujuan untuk menganalisis bagaimana pengaruh motivasi dan kepuasan kerja terhadap kinerja Personel Polri Direktorat Reserse Kriminal Khusus Kepolisian Daerah Sumatera Selatan. Model penelitian terapan metode survey, menggunakan 82 sample dari populasi 92 pegawai Personel Polri Direktorat Reserse Kriminal Khusus Kepolisian Daerah Sumatera Selatan, dengan menggunakan analisis regresi berganda (multiple regression analisys). Teknis analisis data menggunakan statistika deskriptif dan statistika inferensial. Dalam penelitian ini, jenis data yang digunakan adalah data primer dan data skunder. Teknik pengumpulan data menggunakan kuesioner, wawancara, observasi dan dokumentasi. Pengujian hipotesis melalui uji $t$ dan uji $F$ menggunakan tools analysis SPSS. Hasil pengolahan data menggunakan SPSS 25, menggunakan uji t bahwa thitung sebesar 4.021> dengan t tabel 1.993 dan tingkat signifikansi 0,025 <0,05 bahwa terdapat pengaruh positif dan signifikan motivasi terhadap kinerja; bahwa thitung sebesar 3.025> dengan $t$ tabel 1.993 dan tingkat signifikansi 0,041<0,05 bahwa terdapat pengaruh positif dan signifikan kepuasan kerja terhadap kinerja; dan menggunakan uji $F$ bahwa $F$ hitung sebesar 7.194> dengan $F$ tabel 2,683 dan tingkat signifikansi 0,00<0,05 bahwa terdapat pengaruh positif dan signifkan pola motivasi dan kepuasan kerja secara
\end{abstract}


bersama-sama terhadap kinerja, dengan besaran koefisien determinasi 49,3\% selebihnya dipengaruhi oleh variabel lain. Hasil penelitian bahwa motivasi dan kepuasan kerja berpengaruh positif dan signifikan terhadap kinerja baik secara parsial ataupun simultan. Strategi pengembangan karier Personel Polri Direktorat Reserse Kriminal Khusus Kepolisian Daerah Sumatera Selatan sangat ditentukan dari memberikan Renumerasi yang diterima personil tepat waktu sesuai ketentuan yang berlaku, baru kemudian meningkatkan motivasi kerja personil dengan teknik pimpinan selalu memberikan apresiasi atas prestasi kerja personil.

Kata Kunci: Motivasi, Kepuasan Kerja, Kinerja.

\section{A. PENDAHULUAN}

\section{Latar Belakang}

Berdasarkan Undang-undang Nomor 2 tahun 2002 tentang Kepolisian Negara Republik Indonesia pada Pasal 1 ayat 2 bahwa Anggota Kepolisian Negara Republik Indonesia adalah pegawai negeri pada Kepolisian Negara Republik Indonesia. Sebelum tahun 2011 hanya ada satuan kerja Direktorat Reserse Kriminal yang lebih dikenal dengan Dit Reskrim Polda Sumsel yang membawahi kesatuan Reserse Kriminal (Reskrim) di daerah-daerah atau Polres. Dan pada tahun 2011 Direktorat Reserse Kriminal (Dit Reskrim) Polda Sumatera Selatan dipecah menjadi 3 (tiga) bagian, yaitu Direktorat Reserse Kriminal Umum (Dit Reskrim Um), Direktorat Reserse Narkoba (Dit Res Narkoba) dan Direktorat Reserse Kriminal Khusus (Dit Reskrims Sus) sendiri. Dan Direktorat Reserse Kriminal Khusus merupakan salah satu satuan kerja di Polda Sumatera Selatan dari 33 satuan kerja di Polda Sumatera Selatan.

Direktorat Reserse Kriminal Khusus adalah unsur pelaksana utama Kepolisian Negara Republik Indonesia (Polri) pada tingkat Polda yang dipimpin oleh Direktur Reserse Kriminal Khusus (Dir Reskrim) yang bertanggung jawab di bawah Kepala Kepolisian Polda Sumatera Selatan (Kapolda Sumsel). Direktorat Reserse Kriminal Khusus Polda Sumatera Selatan (Dit Reskrimsus Polda Sumsel) bertugas dalam membina dan menyelenggarakan fungsi penyelidikan dan penyidikan tindak pidana, melakukan pengawasan dan pengendalian penyidikan serta dalam rangka penegakan hukum serta pengelolaan informasi kriminal di Sumatera Selatan. Dalam pelaksanaan penyelidikan dan penyidikan tindak pidana tidak cukup hanya dengan personil yang memadai tetapi harus ditunjang dengan pola-pola pembinaan yang intensif, terencana dan terukur bagi semua karyawan koperasi. Hal ini disebabkan adanya tantangan mengingat banyaknya masalah yang harus dihadapi oleh personil Direktorat Reserse Kriminal Khusus Polda Sumatera Selatan seperti kurangnya personil yang mampu dan bisa melaksanakan tindakan penyidikan dengan baik dan maksimal sesuai dengan ketentuan yang ada. Hingga kini belum sepenuhnya dapat dilaksanakan terutama dalam upaya mensejahterakan anggotanya serta kulaitas personil Direktorat Reserse Kriminal Khusus yang harus terus ditingkatkan.

Personil Direktorat Reserse Kriminal Khusus adalah orang-orang yang melakukan penyelidikan, penyidikan terhadap tindak pidana secara khusus di Provinsi Sumatera Selatan. Hasil survey sementara yang dilakukan oleh personil Direktorat Reserse Kriminal Khusus, menunjukan bahwa masih banyaknya masalah yang dihadapi secara internal dan secara eksternal. Masalah internal adalah menyangkut rendahnya kualitas personil Direktorat Reserse Kriminal Khusus Polda Sumatera Selatan sedangkan masalah eksternal antara lain menyangkut faktor kebijakan pimpinan atau atasan di satuan kerja itu sendiri. Pendayagunaan personil perlu dikelola secara profesional agar terwujudnya keseimbangan antara kebutuhan personil dengan kepentingan dan pelayanan Direktorat Resrse Kriminal Khusus Polda Sumatera Selatan kepada masyarakat. Keseimbangan tersebut merupakan kunci utama dalam pendayagunaan sumber daya personil dalam mencapai kinerja yang maksimal. Dengan demikian semakin disadari bahwa dalam suatu satuan kerja, SDM merupakan unsur yang paling penting, seperti yang diungkapkan oleh 
Hardyansyah (2002) bahwa manusia sebagai tenaga kerja dalam organisasi mempunyai peran yang penting dalam mencapai tujuan dan memberikan pelayanan yang baik bagi organisasi dan masyarakat. Karyawan (account officer) merupakan faktor produksi yang paling utama, karena itu harus mempunyai kemamuan dan kemampuan dalam melaksanakan tugastugas yang dibebankan dari Direktorat Resrse Kriminal Khusus Polda Sumatera Selatan.

Kinerja karyawan adalah hal yang mempengaruhi seberapa banyak mereka memberi kontribusi kepada organisasi. Perbaikan kinerja individu maupun kelompok menjadi pusat perhatian dalam upaya meningkatkan kinerja organisasi (Malthis dan Jackson, 2001). Menurut Dessles (2003) sumber daya manusia yang handal mampu menolong organisasi menghadapi tantangan persaingan global. Personil atau anggota adalah pelaksana utama setiap organisasi terhadap sarana, prasarana dan infrastruktur yang ada. Personil merupakan salah satu faktor kunci orgnisasi yang harus diperhatikan karena selalu mengalami berbagai dinamika di dalam organisasi. Dari pernyataan tersebut dspat disimpulkan untuk meningkatkan kinerja organisasi, terlebih dahulu memperbaiki kinerja individu. Namun banyak faktor yang menentukan kinerja individu, yaitu rekan kerja, kemampuan, pengawasan, peraturan perusahaan, motivasi dan pelatihan (Admont, 2010).

Faktor yang dapat meningkatkan kinerja personil adalah bagaimana cara pimpinan atau atasan memotivasi seorang karyawan agar dapat meningkatkan kinerjanya dan dapat dilakukan dengan cara memotivasi seorang personil Polri dan meningkatkan kepuasan kerja personil Direktorat Reserse Kriminal Khusus Polda Sumatera Selatan. Motivasi kerja dan kepuasan kerja merupakan faktor sangat penting dalam meningkatkan kinerja karyawan. Motivasi adalah proses yang dinamis dimana setiap orang dapat motivasi oleh hal-hal yang berbeda. Gomes (2003) mendifinasikan motivasi sebagai perilaku yang ditunjukan pada sasarean. Motivasi berkaitan dengan tingkat usaha yang dilakukan oleh seseorang dalam mengejar suatu tujuan dan berkaitan erat dengan kepuasan pekerja dan performansi pekerjaan.

Menurut Hezberg (2008) dalam Teck Hong dan Wahed (2011) ada dua jenis faktor yang mendorong seseorang untuk berusaha mencapai kepuasan dan menjauhkan diri dari ketidakpuasan. Dua faktor itu disebutnya factor hygiene (faktor ekstrinsik) dan faktor motivator (faktor intrinsik). Faktor hygiene memotivasi seseorang untuk keluar dari ketidakpuasan. Faktor eksternal tersebut termasuk gaji, keadaan atau kondisi kerja, pengawasan, hubungan interpersonal, kebijakan dan administrasi. Faktor motivator memotivasi seseorang untuk berusaha mencapai kepuasan, yang termasuk di dalamnya adalah pencapaian atau penyelesaian pada suatu pekerjaan, pengenalan untuk menyelesaikan pekerjaan, sifat pekerjaan dan tugas itu sendiri, kelanjutan dan pertumbuhan dalam kemampuan pekerjaan. Faktor-faktor motivasi yang bersifat internal dengan pekerjaan seperti prestasi, pengakuan, tanggung jawab, sifat pekerjaan dan pertumbuhan pribadi dan kemajuan secara signifikan berhubungan dengan kepuasan kerja karyawan (Ncube dan Samuel, 2014).

Maka dari uraian latar belakang diatas, peneliti ingin mengetahui seberapa besar faktor motivasi dan kepuasan kerja memengaruhi kinerja anggota Polri Direktorat Reserse Kriminal Khusus Kepolisian Daerah Sumatera Selatan, dengan mengambil judul "Pengaruh Motivasi Dan Kepuasan Kerja Terhadap Kinerja Personil Direktorat Reserse Kriminal Khusus Polda Sumatera Selatan".

\section{Perumusan Masalah}

Berdasarkan uraian pada latar belakang di atas penulis merumuskan permasalahan sebagai berikut:

a. Bagaimanakah pengaruh motivasi terhadap kinerja Personel Polri Direktorat Reserse Kriminal Khusus Kepolisian Daerah Sumatera Selatan?

b. Bagaimanakah pengaruh kepuasan kerja terhadap kinerja Personel Polri Direktorat Reserse Kriminal Khusus Kepolisian Daerah Sumatera Selatan? 
c. Bagaimanakah pengaruh motivasi dan kepuasan kerja secara bersama-sama terhadap kinerja Personel Polri Direktorat Reserse Kriminal Khusus Kepolisian Daerah Sumatera Selatan?

\section{B. TINJAUAN PUSTAKA}

\section{Pengertian Motivasi}

Agar pengertian motivasi ini lebih jelas ada beberapa pendapat ahli mengenai definisidefinisi motivasi diantaranya adalah: Menurut Frederick Herzberg dikutip dalam Doni Juni Priansa (2014:171) menyatakan bahwa:

"Motivasi adalah faktor-faktor yang sifatnya ekstrinsik bersumber dari luar diri yang turut menentukan perilaku seseorang dalam kehidupan seseorang"

Menurut Stephen P. Robbins dalam Donni Juni Priansa (2014:171), menyatakan bahwa:

"Motivasi kerja sebagai kesediaan untuk melaksanakan upaya tingkat tinggi untuk mencapai tujuan-tujuan keorganisasian yang dikondisikan oleh kemampuan upaya untuk memenuhi kebutuhan individual tertentu".

Menurut Veithzal Rivai (2011:837), mendifinisikan bahwa:

"Motivasi adalah serangkaian sikap dan nilai-nilai yang mempengaruhi individu tuntuk mencapai hal yang spesifik sesuai dengan tujuan individu. Sikap dan nilai tersebut merupakan suatu yang invisible yang memberikan kekuatan untuk mendorong individu bertingkah laku dalam mencapai tujuan”.

\section{Kepuasan Kerja}

Noe et al. (2011) mendefinisikan variabel ini sebagai perasaan senang sebagai akibat persepsi bahwa pekerjaan seseorang memenuhi atau memungkinkan terpenuhinya nilai-nilai kerja penting bagi orang itu. Definisi ini mereflesikan tiga aspek penting, yaitu:

1. Kepuasan kerja merupakan fungsi nilai yang didefinisikan sebagai apa yang ingin diperoleh seseorang baik sadar maupun tidak sadar.

2. Beragam personil memiliki pandangan yang juga berbeda-beda menyangkut nilai- nilai yang dirasa penting dan sangat berpengaruh terhadap penentuan sifat dan derajat kepuasan mereka.

3. Persepsi individu dapat saja bukan merupaka refleksi yang sepenuhnya akurat terhadap realitas, dan beragam orang dapat dapat memandang situasi yang sama secara berbeda - beda.

\section{Kinerja}

Menurut Maharjan (2012), kinerja adalah suatu hasil yang dicapai karena termotivasi dengan pekerjaan dan puas dengan pekerjaan yang mereka lakukan. Tiap individu cenderung akan dihadapkan pada hal-hal yang mungkin tidak diduga sebelumnya di dalam proses mencapai kebutuhan yang diinginkan sehingga melalui bekerja dan pertumbuhan pengalaman, seseorang akan memperoleh kemajuan dalam hidupnya.

\section{Penelitian Terdahulu}

Hasil telusuran beberapa jurnal yang adalah pebelitian terdahulu yang relevan dengan penelitian ini digambarkan dalam tabel berkut,

Tabel 2.1 Penelitian Terdahulu

\begin{tabular}{|c|c|c|}
\hline No. & Peneliti & Hasil Penelitian \\
\hline 1 & $\begin{array}{l}\text { Ferdiansyah, } \\
2011 \\
\text { Pengaruh } \\
\text { Motivasi Dan } \\
\text { Kepuasan } \\
\text { Kerjaterhadap } \\
\text { Kinerja } \\
\text { Karyawan } \\
\text { Pengaruh } \\
\text { Motivasi Dan } \\
\text { Kepuasan } \\
\text { Kerja } \\
\text { Terhadap } \\
\text { Kinerja } \\
\text { Karyawan, } \\
\text { Binus } \\
\text { Business } \\
\text { Review Vol. } \\
2 \text { No. 1 Mei } \\
\text { 2011: } 379- \\
386\end{array}$ & $\begin{array}{lr}\text { (1) } \mathrm{R} \text { square adalah } 0.530 . \\
\text { Hal ini berarti kinerja } \\
\text { karyawan } r \text { dapat } \\
\text { dipengaruhi } \\
\text { motivasi sebesar } 53 \% \text {. } \\
\text { Angka } \mathrm{R} \text { pada model } \\
\text { summary menunjukkan } \\
\text { bahwa kolerasi motivasi } \\
\text { (X1) dengan kinerja }(Y) \\
\text { adalah 0.728. Angka } \\
\text { 0.728 menjukkan } \\
\text { hubungan yang kuat. } \\
\text { (2) square adalah 0.106. } \\
\text { berarti kinerja karyawan } \\
\text { dapat dipengaruhi oleh } \\
\text { kepuasan kerja sebesar } \\
\text { 10.6\%. Angka R pada } \\
\text { model summary } \\
\text { menunjukkan bahwa } \\
\text { kolerasi kepuasan kerja } \\
\text { (X2) dengan kinerja }(Y) \\
\text { adalah 0.325. Angka } \\
\text { 0.325 menunjukkan } \\
\text { hubungan yang rendah. } \\
\text { (3) Angka R square pada } \\
\text { model summary adalah } \\
\text { 0.545. Hal ini berarti } \\
\text { kinerja karyawan dapat } \\
\text { dipengaruhi oleh }\end{array}$ \\
\hline
\end{tabular}




\begin{tabular}{|c|c|c|}
\hline & & $\begin{array}{lrr}\text { motivasi } & (X 1) & \text { dan } \\
\text { kepuasan } & \text { kerja } & (X 2) \\
\text { sebesar } & 54.5 \% \\
\text { Sedangkan } & \text { sisanya } \\
\text { sebesar } & 45.5 \% \\
\text { dipengaruhi } & \text { oleh } & \text { faktor } \\
\text { lain. } & \end{array}$ \\
\hline 2 & $\begin{array}{c}\text { Cahyadi, } \\
2018 \\
\text { Pengaruh } \\
\text { Kepuasan } \\
\text { Kerja } \\
\text { Terhadap } \\
\text { Kinerja } \\
\text { Karyawan } \\
\text { Non Medis } \\
\text { Rs Islam } \\
\text { Siti } \\
\text { Khadijah } \\
\text { Palembang), }\end{array}$ & $\begin{array}{l}\text { Kepuasan Kerja } \\
\text { mempunyai pengaruh } \\
\text { terhadap variabel } \\
\text { terikatnya yaitu Kinerja } \\
\text { Karyawan. Hal ini } \\
\text { dibuktikan dari nilai t- } \\
\text { hitung sebesar }(2,309)> \\
\text { ttabel }(2,024) \text { dengan } \\
\text { tingkatan signifikansi } \\
\text { sebesar } 0,026 \text { lebih kecil } \\
\text { dari } 0,05(0,026<0,05) \text {, }\end{array}$ \\
\hline
\end{tabular}

\section{Kerangka Pemikiran}

Berdasarkan teori pada tinjauan pustaka sebagaimana telah diuraikan pada sebelumnya, dapat disusun suatu kerangka konseptual untuk menganalisis pengaruh remunerasi, motivasi dan disiplin kerja terhadap kinerja.

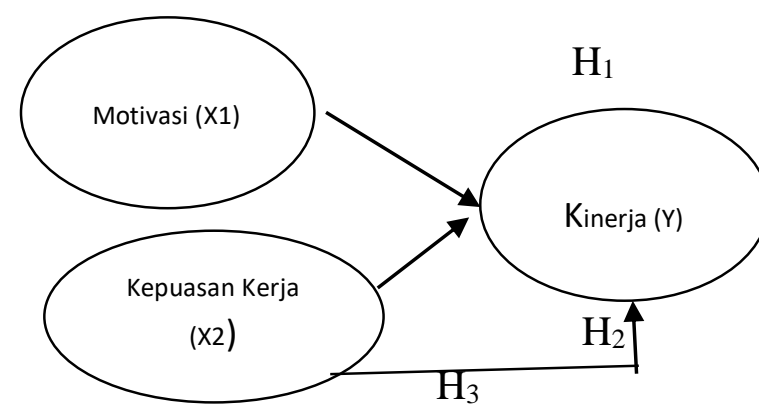

Gambar 2.1. Bagan Alur Penelitian

\section{METODOLOGI PENELITIAN}

\section{Populasi dan Sampel.}

Sasaran penelitian ini seluruh personil Ditreskrimsus Polda Sumsel dengan jumlah 92 orang untuk personil Ditreskrimsus Polda Sumsel. Namun dari 92 kuesioner yang disebar hanya sebanyak 82 kuesioner yang kembali, maka sampel penelitian yang diambil adalah sebanyak 82 pegawai.

\section{Teknik Analisis Data}

Dalam penelitian ini digunakan metode analisis regresi berganda (multiple regression analisys), yaitu regresi dimana variable terikat (Y) dihubungkan atau dijelaskan oleh lebih dari satu variabel. Analisis regresi berganda digunakan untuk menganalisis pengaruh variabel bebas yang terdiri dari motivasi $\left(\mathrm{X}_{1}\right)$ dan kepuasan kerja $\left(\mathrm{X}_{2}\right)$ terhadap variabel terikat, yaitu Kinerja (Y).

\section{Pengujian Instrumen Penelitian \\ a. Uji Validitas}

Untuk menguji validitas alat ukur, terlebih dulu dicari harga korelasi antara bagian-bagian dari alat ukur secara keseluruhan dengan cara mengkorelasikan setiap butir alat ukur dengan skor total yang merupakan jumlah tiap skor butir. Untuk menghitung validitas menggunakan teknik korelasi Pearson product moment.

Distribusi (Tabel t) untuk a-0,1 dan derajad kebebasan $(\mathrm{d} f=\mathrm{n}-2)$ kaidah keputusan: - $\quad t$ hitung $>\mathrm{t}$ tabel berarti valid sebaliknya

- $\quad \mathrm{t}$ hitung $<\mathrm{t}$ tabel berarti tidak valid

\section{b. Uji Reliabilitas}

Reliabilitas artinya adalah tingkat kepercayaan hasil suatu pengukuran. Pengukuran yang memiliki reliabilitas tinggi, yaitu pengukuran yang mampu memberikan hasil ukur yang terpercaya (reliable). Menurut Triton (2006), tingkat reliabilitas dengan metode Alpha Cronbach's diukur berdasarkan skala Alpha 0 sampai 1. Apabila skala tersebut dikelompokkan ke dalam lima kelas dengan range yang sama, maka ukurlan kemantapan Alpha dapat diinterpretasikan sebagai berikut.

Tabel 3.1 Tingkat Reliabilitas berdasarkan Nilai

\begin{tabular}{|c|c|}
\hline Alpha & Tingkat Reliabilitas \\
\hline $0.00-0.20$ & Kurang Reliabel \\
\hline$<0.20-0.40$ & Agak Reliabel \\
\hline$<0.40-0.60$ & Cukup Reliabel \\
\hline$<0.60-0.80$ & Reliabel \\
\hline$<0.80-1.00$ & Sangat Reliabel \\
\hline
\end{tabular}




\section{Uji Asumsi Klasik}

\section{a. Uji Normalitas}

Uji normalitas digunakan untuk menguji apakah model regresi mempunyai distribusi normal ataukah tidak. Asumsi normalitas merupakan persyaratan yang sangat penting pada pengujian kebermaknaan (signifikansi) koefisien regresi. Model regresi yang baik adalah model regresi yang memiliki distribusi normal atau mendekati normal, sehingga layak dilakukan pengujian secara statistik.

\section{b. Uji Multikolinieritas}

Multikolinieritas merupakan suatu situasi dimana beberapa atau semua variabel bebas berkorelasi kuat. Jika terdapat korelasi yang kuat di antara sesama variabel independen maka konsekuensinya adalah:

1) Koefisien-koefisien regresi menjadi tidak dapat ditaksir.

2) Nilai standar error setiap koefisien regresi menjadi tidak terhingga.

\section{Pengujian Hipotesis}

a. Uji Signifikansi Simultan (Uji Statistik F)

Uji F digunakan untuk mengetahui apakah semua variabel bebas secara bersama-sama dapat berpengaruh terhadap variabel terikat.

\section{b. Uji Hipotesis secara Parsial (Uji \\ Statistik t)}

Uji $\mathrm{t}$ digunakan untuk mengetahui seberapa jauh pengaruh satu variabel independen secara individual dalam menerangkan variasi variabel dependen

\section{c. Uji Koefisien Determinasi $\left(\mathbf{R}^{2}\right)$}

Koefisien determinasi $\left(\mathrm{R}^{2}\right)$ artinya mengukur seberapa jauh kemampuan model dalam menerangkan variasi variabel terikat. Nilai $R^{2}$ yang kecil berarti kemampuan variabel bebas dalam menjelaskan variabel terikat sangat terbatas. Nilai $\mathrm{R}^{2}$ yang mendekati 1 berarti kemampuan variabel bebas memberikan semua informasi yang dibutuhkan untuk memprediksi variasi variabel terikat secara simultan (Ali Muhson, 2015).

\section{Tabel 3.2.}

Kriteria Penerimaan Hipotesis

\begin{tabular}{|c|c|l|c|}
\hline NO & \multicolumn{2}{|c|}{ HIPOTESIS } & KRITERIA \\
\hline \multirow{3}{*}{$\mathrm{H}_{1}$} & Ho & $\begin{array}{l}\text { Tidak terdapat } \\
\text { pengaruh } \\
\text { motivasi } \\
\text { terhadap Kinerja } \\
\text { pesonil }\end{array}$ & $\begin{array}{c}\text { Sign }(\mathrm{P})>0,05 \\
\text { Thitung }<\mathrm{T} \\
\text { tabel }\end{array}$ \\
\hline
\end{tabular}

\begin{tabular}{|c|c|c|c|}
\hline & $\mathrm{Ha}$ & $\begin{array}{l}\text { Terdapat } \\
\text { pengaruh } \\
\text { motivasi } \\
\text { terhadap Kinerja } \\
\text { personil }\end{array}$ & $\begin{array}{c}\text { Sign }(\mathrm{P})<0,05 \\
\mathrm{~T} \text { hitung }>\mathrm{T} \\
\text { tabel }\end{array}$ \\
\hline \multirow{2}{*}{$\mathrm{H}_{2}$} & Но & $\begin{array}{l}\text { Tidak terdapat } \\
\text { pengaruh } \\
\text { Kepuasan kerja } \\
\text { terhadap Kinerja } \\
\text { personil }\end{array}$ & $\begin{array}{c}\text { Sign }(\mathrm{P})>0.05 \\
\mathrm{~T} \text { hitung }<\mathrm{T} \\
\text { tabel }\end{array}$ \\
\hline & $\mathrm{Ha}$ & $\begin{array}{l}\text { Terdapat } \\
\text { pengaruh } \\
\text { kepuasan kerja } \\
\text { terhadap Kinerja } \\
\text { personil }\end{array}$ & $\begin{array}{c}\text { Sign }(\mathrm{P})<0,05 \\
\mathrm{~T} \text { hitung }>\mathrm{T} \\
\text { tabel }\end{array}$ \\
\hline \multirow{2}{*}{$\mathrm{H}_{3}$} & Но & $\begin{array}{l}\text { Tidak terdapat } \\
\text { pengaruh } \\
\text { motivasi dan } \\
\text { kepuasan kerja } \\
\text { secara bersama- } \\
\text { sama terhadap } \\
\text { Kinerja personil }\end{array}$ & $\begin{array}{c}\text { Signifikansi }(\mathrm{P})> \\
0,05 \\
\mathrm{~F} \text { hitung }<\mathrm{F} \text { tabel }\end{array}$ \\
\hline & Ha & $\begin{array}{l}\text { Terdapat } \\
\text { pengaruh } \\
\text { motivasi dan } \\
\text { Kepiasan kerja } \\
\text { secara bersama- } \\
\text { sama terhadap } \\
\text { Kinerja personil }\end{array}$ & $\begin{array}{c}\text { Signifikansi }(\mathrm{P}) \\
<0,05 \\
\text { F hitung }>\text { F tabel }\end{array}$ \\
\hline
\end{tabular}

Sumber; Diolah Peneliti' 2020

\section{HASIL DAN PEMBAHASAN}

\section{Hasil Penelitian \\ a. Hasil Pengujian Instrumen}

Instrumen penelitian sebelum disebarkan kepada responden penelitian, telah diuji cobakan kepada 82 responden yang memiliki karakteristik yang tidak jauh berbeda dengan responden penelitian, hasil pengujian validitas dan reabilitas instrumen penelitian adalah sebagai berikut;

\section{b. Hasil Validasi Instrumen}

Instrumen penelitian telah sahih sebagai alat pengumpul data, setelah dilakukan pengujian validitas instrumen penelitian mengunakan SPSS. Hasilnya membuktikan nilai indeks validitas untuk variabel motivasi, kepuasan kerja maupun kinerja semuanya $>0$, 25. Sehingga hasil survey dapat dilanjutkan untuk pengambilan data penelitian selanjutnya.

\section{c. Uji Reliabilitas Instrumen Penelitian}

Uji reliabilitas ditujukan untuk mengukur apakah instrumen penelitian sudah reliabel sebagai alat pengumpul data. Hasil pengujian reliabilitas hampir seluruh variabel memiliki Cronbachs alfa $>0,70$ sehinga variabel memiliki hubungan dengan indikatornya sangat kuat. Sebagaimana tergambar dalam tabel berikut ini; 
Tabel 4.1

Hasil Pengujian Reliabilitas Variabel Penelitian

\begin{tabular}{|l|c|c|ll|}
\hline VARIABEL & KRITERIA & $\begin{array}{c}\text { CRONBA } \\
\text { CH'A }\end{array}$ & \multicolumn{2}{|l|}{ REKOMENDASI } \\
\hline Motivasi & 0,70 & 0,806 & $\begin{array}{l}\text { Reliabel } \\
\text { kuat }\end{array}$ & Sangat \\
\hline $\begin{array}{l}\text { Kepuasan } \\
\text { Kerja }\end{array}$ & 0,70 & 0,647 & $\begin{array}{l}\text { Reliabel } \\
\text { kuat }\end{array}$ & cukup \\
\hline Kinerja & 0,70 & 0,811 & $\begin{array}{l}\text { Reliabel } \\
\text { kuat }\end{array}$ & Sangat \\
\hline
\end{tabular}

Sumber: Output SPSS diolah'2020

Seluruh variabel penelitian yang digunakan mempunyai hubungan yang cukup sampai dengan hubungan sangat kuat dengan koefisien di atas dari 0,70, sehingga dapat dikatakan bahwa instrumen penelitian telah reliabel dan dapat digunakan di manapun dan kapan saja akan mendapatkan jawaban yang sama.

\section{Pengujian Asumsi Klasik}

a. Pengujian Normalitas Data

Hasil Uji normalitas menggunakan uji plot $P P$ regression standardized residual, distribusi data penelitian telah berdistribusi normal sebagaimana gambar di bawah.

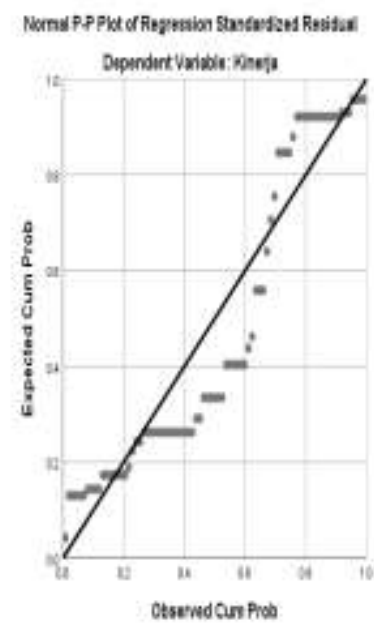

\section{Histogram 4.1 PP Plot Regresion}

Gambar 4.1 menujukkan normalitas data dilihat penyebaran data (titik) pada sumbu diagonal dari grafik menyebar disekitar garis diagonal dan mengikuti arah garis diagonal atau grafik histogramnya menunjukkan pola distribusi normal, maka model regresi memenuhi asumsi normalitas.

\section{b. Uji Linearitas}

Hubungan variabel dependen dengan variabel independen telah linear dalam range tertentu. Hasil uji asumsi linearitas menggunakan SPSS 25, hubungan antar variabel telah linear sebagaimana telah disarikan pada tabel berikut.

Tabel 4.2.

\section{Hasil Pengujian Linearitas}

\begin{tabular}{|l|l|c|c|}
\hline $\begin{array}{c}\text { Variabel } \\
\text { Dependen }\end{array}$ & \multicolumn{1}{|c|}{$\begin{array}{c}\text { Variabel } \\
\text { Independen }\end{array}$} & $\begin{array}{c}\text { Hasil } \\
\text { Pengujian }\end{array}$ & Rekomendasi \\
\hline Motivasi & Kinerja & 0,026 & Linear \\
\hline $\begin{array}{l}\text { Kepuasan } \\
\text { Kerja }\end{array}$ & Kinerja & 0,041 & Linear \\
\hline
\end{tabular}

Sumber: Diolah oleh peneliti (2020)

Tabel 4.2. menunjukkan bahwa hasil pengujian linearitas variabel bahwa hubungan semua variabel telah < dari 0,05 , maka hubungan variabel dependen dan variabel independen seluruhnya telah linear. Sehingga hasil uji linearitas bahwa variabel penelitian telah memenuhi kriteria linearitas. Karenanya dapat dilanjutkan dengan pengolahan data penelitian.

\section{d. Uji Multikolinearitas}

Hasil pengolahan data penelitian menggunakan tools SPSS versions 25, untuk pengujian bahwa hubungan antar variable tidak terjadi multikolinearitas data yang sangat tinggi. Hasil pengujian multikolinearitas data penelitian dengan menggunakan kriteria tolerance dan $V$ Inflations Factors disarikan secara lengkap dalam tabel berikut.

Tabel 43.

Hasil Pengujian Multikolineritas Variabel Penelitian

\begin{tabular}{|l|c|c|c|c|}
\hline \multirow{2}{*}{ Variabel } & \multirow{2}{*}{$\begin{array}{c}\text { Kriteria } \\
\text { VIF }\end{array}$} & \multicolumn{3}{|c|}{ Kabupaten OKI } \\
\cline { 3 - 5 } & $<$ TOL & VIF & Hasil \\
\hline Motivasi & $<10$ & 0.973 & 1.028 & Diterima \\
\hline $\begin{array}{l}\text { Kepuasan } \\
\text { Kerja }\end{array}$ & $<10$ & 0.973 & 1.028 & Diterima \\
\hline
\end{tabular}

Sumber: Diolah oleh peneliti (2020)

Dari tabel 4.3. menunjukkan semua variable penelitian tidak mengambarkan adanya multikolineritas yang sangat ekstrim, 
koefisien toleransi dan VIF $<10$, maka dapat disimpulkan bahwa penelitian ini telah memenuhi asumsi klasik multikolinearitas, sehingga dapat dilanjutkan dengan pengolahan data selanjutnya.

\section{Pengujian Hipotesis}

\section{Hipotesis-1}

$\mathrm{H}_{\mathrm{o}}$ : Tidak Terdapat Pengaruh Motivasi Terhadap Kinerja Ditreskrimum Polda Sumatera Selatan

$\mathrm{H}_{1}$ : Terdapat Pengaruh Motivasi Terhadap KinerjaDitreskrimum Polda Sumatera Selatan

Dari hasil pengolahan data menggunakan SPSS, dan pengujian data menggunakan uji $\mathrm{t}$ bahwa t hitung sebesar 4.021> dengan $t$ tabel 1.993 dan tingkat signifikansi $0,025<0,05$, maka hipotesis Ho ditolak dan H1 diterima maka hasil pengujian hipotesis bahwa terdapat pengaruh positif dan signifikan motivasi terhadap kinerja, sebagaimana dalam tabel berikut.

Tabel 4.4.

\begin{tabular}{|c|c|c|c|c|c|} 
Pengaruh Motivasi Terhadap Kinerja \\
\hline \multirow{4}{*}{ Model } & $\begin{array}{c}\text { Unstandard } \\
\text { ized } \\
\text { Coefficients }\end{array}$ & $\begin{array}{c}\text { Standard } \\
\text { ized } \\
\text { Coefficie } \\
\text { nts }\end{array}$ & \multirow{2}{*}{$\mathrm{t}$} & Sig. \\
\cline { 2 - 6 } & $\mathrm{B}$ & $\begin{array}{c}\text { Std. } \\
\text { Erro } \\
\mathrm{r}\end{array}$ & Beta & & \\
\hline $\begin{array}{c}\text { Motivasi_Ki } \\
\text { nerja }\end{array}$ & $\begin{array}{c}0.62 \\
0\end{array}$ & $\begin{array}{c}0.12 \\
2\end{array}$ & 0.323 & $\begin{array}{c}4.0 \\
21\end{array}$ & 0.0 \\
25
\end{tabular}

Sumber : Diolah oleh peneliti(2020)

Dari tabel 4.4. diketahui bahwa tingkat signifikansi pengaruh motivasi terhadap kinerja adalah $0,025<0,05$ dan t hitung 4,021 >t tabel, maka penelitian ini berhasil mengkonfirmasi teori penelitian pengaruh motivasi terhadap kinerja dapat dibuktikan.

\section{Hipotesis-2}

Ho: Tidak Terdapat Pengaruh Kepuasan Kerja Terhadap KinerjaDitreskrimum Polda Sumatera Selatan

H1: Terdapat Pengaruh Kepuasan Kerja Terhadap KinerjaDitreskrimum Polda Sumatera Selatan

Dari hasil pengolahan data menggunakan SPSS, dan pengujian data menggunakan uji $\mathrm{t}$ bahwa t hitung sebesar 3.025> dengan $t$ tabel
1.993 dan tingkat signifikansi $0,041<0,05$, maka hipotesis Ho ditolak dan H1 diterima maka hasil pengujian hipotesis bahwa terdapat pengaruh positif dan signifikan kepuasan kerja terhadap kinerja, sebagaimana dalam tabel berikut.

Tabel 4.5.

Pengaruh kepuasan Kerja Terhadap Kinerja

\begin{tabular}{|c|c|c|c|c|c|}
\hline \multirow{2}{*}{ Model } & \multicolumn{2}{|c|}{$\begin{array}{c}\text { Unstandard } \\
\text { ized } \\
\text { Coefficients }\end{array}$} & $\begin{array}{c}\text { Standard } \\
\text { ized } \\
\text { Coefficie } \\
\text { nts }\end{array}$ & \multirow{2}{*}{$\mathrm{t}$} & Sig. \\
\cline { 2 - 4 } & $\mathrm{B}$ & $\begin{array}{c}\text { Std. } \\
\text { Erro } \\
\mathrm{r}\end{array}$ & Beta & & \\
\hline $\begin{array}{c}\text { Kepuasan+K } \\
\text { inerja }\end{array}$ & $\begin{array}{c}0.42 \\
7\end{array}$ & $\begin{array}{c}0.32 \\
2\end{array}$ & 0.532 & 26 & 41 \\
\hline
\end{tabular}

Sumber: Diolah oleh peneliti (2020)

Dari tabel 4.5. diketahui bahwa tingkat signifikansi pengaruh kepuasan kerja terhadap kinerjaadalah $0,041<0,05$ dan $\mathrm{t}$ hitung 3,026>t tabel, maka penelitian ini berhasil mengkonfirmasi teori penelitian pengaruh kepuasan kerja terhadap kinerja dapat dibuktikan.

\section{Hipotesis-3}

Ho: Tidak Terdapat Pengaruh Motivasi dan kepuasan Kerja secara besama-sama

Terhadap Kinerja Ditreskrimum Polda Sumatera Selatan

H1: Terdapat Pengaruh Motivasi dan kepuasan Kerja secara besama-sama

Terhadap Kinerja Ditreskrimum Polda Sumatera Selatan

Motivasi dan kepuasan Kerja berpengaruh secara bersama-sama terhadap kinerja Hasil pengolahan data menggunakan SPSS, dengan menggunakan uji $\mathrm{F}$ bahwa $\mathrm{F}$ hitung sebesar 7.194> dengan $\mathrm{F}$ tabel 2,683 dan tingkat signifikansi $0,00<0,05$, maka hipotesis bahwa Ho ditolak dan $\mathrm{H} 1$ diterima, dengan demikian hasil pengujian hipotesis dapat mengkonfirmasi terdapat Motivasi dan kepuasan Kerja berpengaruh terhadap kinerja sebagaimana tergambar dalam tabel berikut ini. 
Tabel 4.6.

Pengaruh Motivasi dan kepuasan Kerja secara Bersama sama terhadap kinerja

\begin{tabular}{|c|c|c|c|c|c|}
\hline Model & $\begin{array}{c}\text { Sum of } \\
\text { Square } \\
\mathrm{S}\end{array}$ & Df & $\begin{array}{c}\text { Mean } \\
\text { Square }\end{array}$ & $\mathrm{F}$ & Sig. \\
\hline $\begin{array}{c}\text { Regressi } \\
\text { on }\end{array}$ & $\begin{array}{c}561.3 \\
73\end{array}$ & 3 & $\begin{array}{c}254.1 \\
23\end{array}$ & $\begin{array}{c}7.19 \\
74\end{array}$ & $\begin{array}{c}.00 \\
0\end{array}$ \\
\hline
\end{tabular}

Sumber: Diolah oleh peneliti (2020)

Dengan demikian maka hasil uji hipotesis3 dapat mengkonfirmasi teori bahwa terdapat pengaruh Motivasi dan kepuasan Kerja secara bersama-sama terhadap kinerja.

\section{Simpulan dan Implikasi Manajerial}

\section{Kesimpulan}

Benang merah yang dapat ditarik dari hasil penelitian ini sebagai kesimpulan penelitian adalah sebagai berikut.

1) Motivasi personil akan meningkat ketika hasil kerjanya mendapatkan pengakuan oleh pimpinan, dan kinerjapun ikut meningkat apabila pimpinan memberikan apresiasi atas kerja personil.

2) Bahwa pemberian renumerasi yang diterima pada waktunya dan sesuai yang ditentukan dapat meningkatkan motivasi personil, berpengaruh secara signifikan terhadap kinerja personil sepanjang pimpinan memberikan apresiasi atas prestasi kerja yang dilaksanakan oleh personil.

\section{Implikasi Manajerial}

Strategi manajerial yang dapat dijalankan oleh pimpinan Ditreskrimum Polda Sumatera Selatandalam rangka meningkatkan kinerja personil Pada Ditreskrimum Polda Sumatera Selatan melalui membangun kepuasan kerja telebih dahulu dengan memberikan Renumerasi yang diterima personil tepat waktu sesuai ketentuan yang berlaku, baru kemudian meningkatkan motivasi kerja personil dengan teknik pimpinan selalu memberikan apresiasi atas prestasi kerja personil, pada gilirannya akan berdampak terhadap kinerja personil melalui memberikan apresiasi prestasi kerja personil oleh pimpinan, sehingga personil memiliki kinerja yang mampu menyelesaikan pekerjaan lebih cepat dari waktunya.

\section{Daftar Pustaka}

Achmad Fadhil, 2013, Pengaruh Motivasi dan Kepuasan Kerja terhadap Kinerja Karyawan Ajb Bumiputera

Cecep Hidayat 1;2011. Ferdiansyah Pengaruh Motivasi Dan Kepuasan Kerjaterhadap Kinerja Karyawan Pengaruh Motivasi Dan Kepuasan Kerja Terhadap Kinerja Karyawan, Binus Business Review Vol. 2 No. 1 Mei 2011: 379-386

Dwi Rahmawati, 2019. Pengaruh Motivasi Kerja Dan Insentif Terhadap Kinerja Pegawai Dinas Pendapatan Daerah Provinsi Lampung, Jurnal DINAMIKA Vol. 5 No. 2 - Desember2019 | ISSN:2460-3643 P 117-129

Firdaus, F. Z. 2018. Aplikasi Metodologi Penelitian. Yogyakarta: Penerbit Deepublish CV Budi Utama.

Ghozali, Imam, 2004, Model Persamaan Struktural, Konsep dan Aplikasi dengan Program AMOS, Semarang, UNDIP.

Gibson, James, L; John, M, Ivancevich dan J, H, Donelly, 2004, Organisasi dan Manajemen, Perilaku, Struktur, Proses, Terj, Djoerban Wahid, Jakarta: Erlangga,

Greenberg, Levald dan Baron, Robert A, 2000. Perilaku Organisasi, penerjemah Handayana Pujatmaka, Jakarta Prentice Hall.

Hasibuan, S, P, Malayu, 2011 Manajemen Sumber Daya Manusia Dasar dan Kunci Keberhasilan, Jakarta: PT. Toko Gunung Agung,

2000, Manajemen Sumber Daya Manusia, Jakarta: Bumi Aksara,

Indrarini, 2009, Pengaruh Motivasi dan Kepuasan Kerja terhadap Kinerja Dosen Akademi Swasta di Semarang

Jogiyanto, 2011, Konsep Dan Aplikasi Structural Equation Modeling, Berbasis 
Varian Dalam Penelitian Bisnis, Zamzam, F., \& Aravik, H. 2016. Manajemen Yogyakarta, YKPN. SDM Berbasis Syariah, Bogor, Penerbit

Lukmanul Hakim, 2013, Pengaruh Motivasi RWTC Succes dan Kepuasan Kerja terhadap Kinerja Karyawan PT. PLN Rayon Simpang

Riski Damayanti1, Agustina Hanafi2, \& Afriyadi Cahyadi3, 2018 Pengaruh Kepuasan Kerja Terhadap Kinerja Karyawan (Studi Kasus Karyawan Non Medis Rs Islam Siti Khadijah Palembang), Jembatan - Jurnal Ilmiah Manajemen Bisnis Dan Terapan Tahun Xv No 2, Oktober 2018, P 72-86

Robbins, Stephen P, 2001, Perilaku Organisasi, Penerjemah Diana Angelina, Jakarta Prenhallindo.

Robbins,2008 The Truth About Managing People, Second EditionUpper Sadle River, New Jersey: Pearson Education, Inc.

2000, Organizational Behavior, 9th Ed, New Jersey Prentice Hall.

Ruri Aprianto, 2018, Pengaruh Motivasi dan Kepuasan Kerja terhadap Kinerja Karyawan PT. Indosis Printingdo

Sugiyono,2003. Statistik untuk Penelitian, Bandung, Alfabeta.

2010. Metode Penelitian Kuantitatif, Kualitatif dan $R \& D$, Bandung Alfabeta

Sugiyono, 2001, Metode Penelitian Administrasi, Bandung: Alfabeta

Trihendradi, 2009. SPSS 16 Step by Step Analisis Data Statistik, Yogyakarta Penerbit Andi Offset.

SPSS 15 Statistik Inferen, Teori Dasar \& Aplikasinya, Yogyakarta, Penerbit Andi Offset.

Zamzam, Fakhry,2015. Teknik Dasar Penulisan Proposal Tesis.

Palembang, Penerbit Noerfikri

Zamzam, Fakhry, 2017, Manajemen Iklim Organisasi, Bogor, Penerbit CV. RWTC Success-Global Price Inc 